\section{MARKETING NA CIÊNCIA DA INFORMAÇÃO BRASILEIRA: quatro décadas de produção}

\author{
Jorge Moisés Kroll do Prado* \\ Adilson Luiz Pinto
}

\section{RESUMO}

\begin{abstract}
Este artigo traz um levantamento e análise da produção intelectual brasileira sobre Marketing em fontes de informação da Ciência da Informação. Uma pesquisa exploratória e inicialmente quantitativa foi realizada em todos os periódicos científicos em acesso aberto ativos da Ciência da Informação, numa cobertura cronológica de 1972 a dezembro de 2017. Em seguida, o levantamento é realizado nos bancos de dissertações e teses do Instituto Brasileiro de Informação Científica e Tecnológica (IBICT) e da Coordenação de Aperfeiçoamento de Pessoal de Nível Superior (Capes), sem delimitação temporal. A pesquisa finaliza-se numa terceira fonte de informação, que são os anais do Encontro Nacional de Pesquisa em Ciência da Informação (Enancib) dos últimos sete anos. A todos os dados levantados, foi realizada uma análise qualitativa com a finalidade de apontar algumas características da produção. Verificou-se que há uma forte relação de se associar marketing com a comunicação, divulgação e tecnologia em diferentes tipologias de bibliotecas (universitárias, escolares, públicas e especializadas) e em poucas outras unidades de informação, como centros de pesquisa. Raros são os textos que buscaram refletir sobre o conceito de maneira empírica, com contribuições e relações junto com a Ciência da Informação.
\end{abstract}

Palavras-chave: Marketing. Ciência da Informação. Produção científica.
* Mestre em Gestão de Unidades de Informação pela Universidade Federal de Santa Catarina, Brasil. Doutorando no Programa de Pós-Graduação em Ciência da Informação da Universidade Federal de Santa Catarina, Brasil. Coordenador do Setor de Criação e Disseminação do Conhecimento do Serviço Nacional de Aprendizagem Comercial de Santa Catarina, Brasil. E-mail: jorge.exlibris@gmail.com.

** Doutor em Documentação pela Universidade Carlos III, Espanha. Professor da Universidade Federal da Santa Catarina, Brasil. Coordenador do Programa de Pós-Graduação em Ciência da Informação da Universidade Federal de Santa Catarina, Brasil.

E-mail: adilson.pinto@ufsc.br.

\section{INTRODUÇÃO}

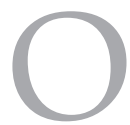
Marketing é uma área de estudo recente, com início conceitual no início do século XX com as contribuições de teóricos e de profissionais do mercado (BARTELS, 1976; SHETH; GARDNER; GARRETT, 1988). Um período marcado por descobertas e transformações nos ambientes sociais, econômicos e políticos com significativa repercussão ${ }^{1}$.

Entre tantos destaques, pode-se elencar a linha de montagem e produção de massa, tecnologias midiáticas (rádio, televisão, cinema, telefone), avanços medicinais como antibiótico e contraceptivo, início de um empoderamento feminino na política, a ruptura e nascimento
À medida em que vai se sedimentando, evoluindo no decorrer do tempo e recebendo contribuições de outras áreas, como Psicologia, Sociologia e Economia, percebe-se que o Marketing do início de século XX deixa de ser exclusivo para a lucratividade e aos produtos e passa também a contemplar a experiência do consumidor e as relações de troca (sem se efetivar, necessariamente, lucro). Assim, outros mercados começam a se apropriar da área, como bibliotecas, museus, arquivos, organizações sem fins lucrativos, dentre outras (KOTLER; KELLER,

de novas percepções políticas com influência direta na economia (HAMPTON, 2005; MCLUHAN, 20I I; HOBSBAWN, 2008). 
2012; KOTLER; KARTAJAYA; SETIAWAN, 2010).

É a partir desta nova atribuição que outras áreas do conhecimento se relacionam com o Marketing para seus determinados contextos, sendo uma delas a Ciência da Informação, que tem como objeto de estudo e de trabalho a informação (BORKO, 1968; SHERA; CLEVELAND, 1977; ZINS, 2007). Marcada fortemente por seu caráter interdisciplinar, o campo de estudo também se aproxima de reflexões provenientes da Computação, Comunicação, Biblioteconomia, Jornalismo, Administração, Sociologia e outros.

Desta forma, o objetivo deste artigo é o de trazer um mapeamento da produção científica sobre Marketing na Ciência da Informação por pesquisadores brasileiros desta área. Justifica-se pela necessidade de elencar quais as principais abordagens utilizadas por este público e assim ter um reconhecimento sobre lacunas que podem vir a ser pesquisadas pela comunidade acadêmica.

As fontes de informação utilizadas para alcançar este objetivo, a partir de uma pesquisa qualiquantitativa em modo exploratório são: a) artigos de periódicos científicos brasileiros em atividade em acesso aberto da Ciência da Informação, desde o lançamento do primeiro periódico da área (1972); b) dissertações e teses de programas de pós-graduação em Ciência da Informação, sem delimitação cronológica e c) anais do Encontro Nacional de Pesquisa em Ciência da Informação a partir de 2010.

\section{A EVOLUÇÃo dOS CONCEITOS DE MARKETING}

O trabalho de construir um conceito e que este seja adotado e replicado pela comunidade científica ou de prática, é bastante árduo. Isso, em algumas partes, é decorrente justamente destas comunidades, que atribuem seus olhares distintos, numa eterna remodelagem. Um conceito que se encaixa nesta dinâmica é o do marketing.

Sua origem conceitual remonta ao início do século passado, o qual ainda passava por resquícios de uma transformação econômica ocasionada pela Revolução Industrial, que mudou os rumos de produzir e vender mercadorias. Esse contexto foi essencial para se começar a pensar de modo estratégico um posicionamento competitivo no mercado. Um período que trouxe severas mudanças no ambiente e no modo de pensar que primeiramente nos Estados Unidos, além de trazer um desenvolvimento de mercado, também revolucionou e criou novas atitudes em negócios (BARTELS, 1976).

O desenvolvimento do marketing é resultado de uma série de circunstâncias: o ambiente traz um novo foco para as práticas de mercado; com a produção industrial novos produtos e serviços são criados onde a população começa a agregar um valor social e o gestor envolvido com o trabalho de marketing precisa engajar o consumidor e sua empresa (BARTELS, 1976). Obviamente que isso não é reflexão de poucos anos, mas sim de um trabalho intensivo aberto às mudanças que o mercado estabelece. Wilkie e Moore (2003) conseguiram mapeá-las em quatro eras que resumem as abordagens: i) Fundando o marketing (19001920): surgem os primeiros cursos com o termo no título, foco na distribuição de produtos; ii) Formalizando o campo (1920-1950): infraestrutura conceitual começa a ser desenvolvida a partir de conferências, periódicos, associação profissional e o estabelecimento de princípios de marketing; iii) Mudança de paradigma (1950-1980): emergem duas perspectivas, sendo uma administrativa e outra das ciências quantitativas, ambas para compreender o futuro do conhecimento em marketing e; iv) Intensificação das mudanças (1980-atual): contribuições de outras áreas do conhecimento ficam mais evidentes para atender um mercado cada vez mais competitivo, já os pesquisadores são pressionados a publicar de modo a fortalecer as reflexões teóricas.

É por conta disso que a literatura sobre marketing tem tantas subdivisões e classificações, justamente para entender estas mudanças, aplicá-las e delimitá-las numa linha do tempo. Algumas delas tem uma forte característica econômica (LAS CASAS, 2004), outras com um olhar mais social (BAGOZZI, 1974; 1975a; 1975b; GRÖNROOS, 2013).

Já no universo acadêmico, o marketing é repleto de embates que tentam defini-lo como ciência, arte, filosofia, técnica e até mesmo disciplina (VARGO, LUSH, 2004; WEBSTER, 1992; 1994a; 1994b; BARTELS, 1974; HUNT, 1976; KOTLER, LEVY, 1969a; 1969b; LUCK, 1969; KOTLER, 1972). Estas discussões, mesmo que acadêmicas, refletem no mercado dos 
profissionais que trabalham com marketing e este também influencia na academia. Algumas controvérsias latentes podem ser evidenciadas ao longo deste percurso reflexivo (SHETH; GARDNER; GARRETT, 1988): Qual é, ou deveria ser, a perspectiva dominante em marketing? Qual é, ou deveria ser, o relacionamento entre marketing e sociedade? Qual é, ou deveria ser, o domínio do marketing? O marketing é uma ciência ou uma arte padronizada? É possível criar uma teoria geral do marketing?

Dentro deste rol de tentativas de subdivisões e classificações, a qual aqui será brevemente apresentada para contribuir com a fundamentação teórica do conceito, mas sempre trazendo em seu cerne os questionamentos supracitados, estão as doze escolas de pensamento em marketing criadas por Sheth (1988). Justificase a escolha delas pois são as mais recorrentes no estudo da área e a qual deixa mais perceptível a evolução e as mudanças do conceito. Cabe salientar que a ordem das escolas é cronológica e que elas não possuem um término definido, elas mesclam entre si à medida que novas contribuições teóricas e práticas vão surgindo e criando outras novas escolas de pensamento.

As primeiras delas podem ser caracterizadas como não-interativas e de base econômica e são chamadas de Commodity, Funcional e Regional (SHETH; GARDNER; GARRETT, 1988). A primeira escola tinha como objetivo principal a venda de produtos e a classificação dos mesmos. Já a Escola Funcional direcionou seu olhar para o propósito de definir todas as atividades envolvidas em marketing, sendo uma das escolas que mais produziu teoricamente (RYAN, 1935). Por último, dentro desta caracterização, está a Escola Regional, que com o auxílio da Geografia e da Economia objetivou pensar a distância existente entre consumidor e produtor.

Passando para um grupo interativo, mas ainda de caráter econômico, as outras próximas três escolas de marketing são a Institucional, a Funcionalista e a Administrativa; onde são percebidas algumas influências sociais e variáveis psicológicas inerentes às transações de marketing (SHETH; GARDNER; GARRETT, 1988). A Escola Institucional analisará criticamente a estrutura dos canais de marketing (DUDDY; REVZAN, 1947). Uma mudança bastante radical pode ser percebida com a Escola Funcionalista, que defende que o marketing é uma estrutura sistêmica com um sistema comportamental e um mercado heterogêneo (ALDERSON, 1965). Já da Escola Administrativa (ou Gerencial), nascem os conceitos "miopia", "mix de marketing" e "segmentação", utilizados até hoje, que são resultantes do objetivo da escola em trazer teorias econômicas para a prática dos profissionais envolvidos com marketing (SHETH; GARDNER; GARRETT, 1988).

Com características não-interativas e não-econômicas, o terceiro grupo reúne as escolas Comportamento do Consumidor, Ativista e Macromarketing (SHETH; GARDNER; GARRETT, 1988). A primeira destas tem por objetivo analisar o consumidor em todos os âmbitos possíveis nas transações de marketing, inclusive para entender o porquê de um consumidor adquirir determinados produtos em detrimento de outros (SHETH, 1967). Já a Escola Ativista continua a pensar o consumidor, mas com um enfoque no seu bem-estar e satisfação em relação às más práticas de comercialização (BEEM, 1973). A Escola de pensamento Macromarketing encerra este terceiro grupo trazendo à tona o impacto das atividades de marketing na sociedade e vice-versa (HUNT; BURNETT, 1982).

O último grupo tem por características ser interativo e não-econômico, tendo por escolas a das Dinâmicas Organizacionais, Sistemista, Trocas Sociais. Há uma perspectiva interacionista que as envolve, onde tanto os consumidores como os produtores possuem papeis importantes que devem ser entendidos e analisados, com uma mútua interdependência e relações integradas (SHETH; GARDNER; GARRETT, 1988).

A Escola das Dinâmicas Organizacionais busca compreender o canal de distribuição como um espaço onde o vendedor e o distribuidor de matéria-prima precisam unir esforços em torno do objetivo de vendas, mas que mesmo assim competem entre si em torno das recompensas provindas de diferentes negócios (SHETH; GARDNER; GARRETT, 1988). Kuhn (1963) argumenta que o marketing é um grande sistema e que todos os elementos que os envolve, como os canais de distribuição, são subsistemas; desta forma, caracterizando a Escola Sistemista. Para afirmar que o marketing não trabalha somente com o lucro, a Escola das Trocas Sociais vem para garantir que um pensamento deve ser 
voltado para as trocas existentes entre produtor e consumidor, indiferente se envolverá valor monetário ou não (MCINNES, 1964).

Vinte e três anos depois, Sheth (2011) revisita seu texto de 1988 e afirma que, no mínimo, outras três novas perspectivas de marketing surgiram: orientação de marketing, estratégia competitiva e marketing de relacionamento. Em artigo de Vargo e Lusch (2004), onde se propõe uma nova lógica dominante, identifica-se ainda o marketing de serviços, a gestão da qualidade, valor e gestão da cadeia de suprimento, gestão de recursos e análise de redes.

No decorrer de todas estas escolas de pensamento, muitos acadêmicos e profissionais buscaram apresentar uma "teoria geral do marketing", um conceito ideal. Há quatro orientações que foram fundamentais e bastante aparentes na história teórica que são: o marketing orientado ao produto, orientado às vendas, ao consumidor e mais recentemente ao social (SHARMA, 2015).

Pode-se perceber claramente estas orientações nas definições da American Marketing Association, consagrada instituição que consegue atuar de modo a influenciar tanto a academia como o mercado, reunindose a cada quatros para refletir sobre os mesmos (GUNDLACH, 2007; GUNDLACH; WILKIE, 2009. Tradução nossa)

- $\quad$ Primeira definição (1935): "Atividades de negócios envolvidas no fluxo de bens e serviços da produção para o consumo".

- $\quad$ Segunda definição (1960): "O desempenho das atividades de negócios que direcionam o fluxo de bens e serviços dos produtores para os consumidores".

- $\quad$ Terceira definição (1985): “O processo de planejamento e execução da concepção, precificação, promoção e distribuição de ideias, bens e serviços para criar trocas que satisfazem os objetivos individuais e organizacionais".

- Quarta definição (2004): "Marketing é a função organizacional e um conjunto de processos para criar, comunicar e entregar valor para os consumidores e para administrar o relacionamento com o consumidor de forma a beneficiar a organização e stakeholders".

- Quinta definição (2007): “Marketing é a atividade, conjunto de instituições e processos para criação, comunicação, entrega e ofertas de troca que tenham valor para os consumidores, clientes, parceiros e sociedade como um todo".

Uma vez que os conceitos não se limitam a nenhum tipo de organização (se com ou sem finalidade lucrativa), logo, o marketing pode ser aplicado a qualquer contexto em que se necessite realizar a troca ou criar relacionamento com um indivíduo ou comunidade tendo como elemento chave ou de interligação um produto ou serviço.

\section{O OLHAR INTERDISCIPLINAR DA CIÊNCIA DA INFORMAÇÃO}

O conceito de informação pode estar atrelado a diferentes abordagens e áreas do conhecimento, além das manifestações teóricas de cada tempo. Características são atribuídas de modo a melhor organizar estes conceitos, bem como a limitá-los conforme sua abrangência. Um dos autores que trabalhou desta maneira foi Capurro (2003), que aqui será utilizado para conceituar informação, fazendo uma breve reflexão com outros autores que propuseram um olhar semelhante.

Principalmente por conta dos estudos de Shannon e Weaver em 1975, que defendem uma Teoria Matemática da Comunicação, a informação pode ser entendida como algo físico no que tange a transferência de uma mensagem entre o emissor e o receptor (CAPURRO, 2003). Esta transferência de informação envolve três níveis de problemas, que são: o técnico (relativo ao transporte físico), o semântico (relativo à linguagem, à interpretação, aos significados) e o pragmático (sobre a eficácia daquela informação, que impactos ela trará) (ARAÚJO, 2009).

Em seguida, Capurro (2003) afirma que a informação tem um caráter cognitivo que vai depender do conhecimento das pessoas. Alguns anos antes, Buckland (1991) apresenta esta perspectiva ao dividir a informação como algo tangível, bastante semelhante com a proposta de Shannon e Weaver (1975) e como algo intangível, sendo parte de um processo de construção do conhecimento.

Por último, Capurro (2003) explica que a informação tem um paradigma que também é social, decorrente de uma construção coletiva de conhecimento. Araújo (2010) desenvolve que 
este modelo começa a se fundamentar a partir dos anos 1990 como uma crítica ao modelo cognitivista que via a informação como um produto isolado e numênica (como se cada informação fosse parte de um grande quebracabeça e não houvesse relação entre as peças).

É com os ditames destes conceitos que se evidencia um contexto conceitual bastante fluido e mutável, resultante também de um período histórico repleto de transformações e criações. Com pensamentos nascentes na década de 1960, com as reflexões de Taylor (1966), Borko (1968) e Ress e Saracevic (1967), a Ciência da Informação tem em seu cerne o trabalho de estudar "a produção, organização, armazenamento, disseminação e uso da informação" (ARAÚJO, 2009). Considera-se que o registro oficial do termo "ciência da informação" deu-se a partir de eventos organizados pelo Georgia Institute of Technology, que reuniram profissionais de distintas áreas que debateram o surgimento de novas tecnologias da informação (FREIRE, 2006). Decorrente deste período histórico, Borko (1968, p. 3) afirma que a Ciência da Informação "é a disciplina que investiga as propriedades e o comportamento informacional, as forças que governam os fluxos de informação e os significados do processamento da informação, visando à acessibilidade e usabilidade".

Mais recentemente, para Saracevic (1996, p. 47), a Ciência da Informação é

\begin{abstract}
um campo dedicado às questões científicas e à prática profissional voltadas para os problemas da efetiva comunicação do conhecimento e de seus registros entre os seres humanos no contexto social, institucional ou individual do uso e das necessidades de informação.
\end{abstract}

A variedade de propostas conceituais é bastante grande, mas pode-se perceber sempre uma ligação com o conceito apresentado pelo Georgia Institute of Technology. Num estudo com 57 pesquisadores de 16 países diferentes, Zins (2007) observou que há seis grandes concepções ou modelos que trabalham o fenômeno dado/ informação/conhecimento/metaconhecimento com os seguintes domínios: hi-tech, tecnológico, cultural, humano, vivência e físico.

Para atender esta cobertura tão grande, identifica-se uma das principais características da Ciência da Informação a sua natureza interdisciplinar, apontada desde as definições de Borko (1968) e de Saracevic (1970), mesmo que não tenham existido consequências epistemológicas sobre isso, pois foi mais para justificar a presença de profissionais de distintas áreas científicas (ARAÚJO, 2014). Sendo uma ciência pós-moderna, a Ciência da Informação assume um caráter interdisciplinar justamente por este fato, pois além da interdisciplinaridade, ela possui uma estreita ligação com as tecnologias da informação e uma forte dimensão social e humana (SARACEVIC, 1996).

Assim, uma vez que tenhamos apontado algumas definições bastante importantes na história da Ciência da Informação e outras sobre o que é informação, pode-se presumir que muitas outras aproximações, com distintas áreas do conhecimento, podem ser feitas. Neste artigo, é com o Marketing que isso será estabelecido a partir de uma análise da produção nacional sobre o tema.

\section{PROCEDIMENTOS METODOLÓGICOS}

Para apresentar a produção brasileira sobre marketing por pesquisadores da área da Ciência da Informação, três fontes de informação foram consideradas com os seguintes propósitos: a) artigos de periódicos de acesso aberto vinculados a programas de pós-graduação e de instituições da área da Ciência da Informação com o objetivo de trazer uma cobertura mais geral da produção; b) teses e dissertações para visualizar a produção mais densa sobre o assunto; c) anais do Enancib de suas últimas sete edições para apresentar as pesquisas mais recentes da área.

Acerca da produção em periódicos científicos de acesso aberto, a busca foi realizada em janeiro de 2018 pelo termo marketing a partir da ferramenta de busca do próprio sistema OJS. A cobertura da pesquisa inicia em 1972, ano em que foi publicado o primeiro fascículo da Revista Ciência da Informação, o primeiro periódico da área no Brasil, e se encerra em dezembro de 2017.

O quadro 1 apresenta a relação dos 29 periódicos (lista resultante de uma pesquisa exploratória na Plataforma Sucupira, da CAPES, e no Repertório da Produção Periódica Brasileira de Ciência da Informação, projeto mantido entre USP e UFAL) e o ano em que cada um lançou seu primeiro fascículo. 
Quadro 1: Periódicos científicos brasileiros da Ciência da Informação

\begin{tabular}{|l|c|}
\hline \multicolumn{1}{|c|}{ PERIÓDICO } & CRIAÇÃO \\
\hline Ágora & 1985 \\
\hline Analisando em Ciência da Informação & 2013 \\
\hline AtoZ: novas práticas em informação e conhecimento & 2011 \\
\hline Biblios & 1985 \\
\hline Biblionline & 2005 \\
\hline Brazilian Journal of Information Science: Research Trends & 2006 \\
\hline Ciência da Informação & 1972 \\
\hline Ciência da Informação em Revista & 2014 \\
\hline Comunicação e Informação & 1998 \\
\hline Conhecimento em Ação & 2016 \\
\hline Em Questão & 2003 \\
\hline Encontros Bibli & 1996 \\
\hline Folha de Rosto & 2015 \\
\hline InCID - Revista de Ciência da Informação e Documentação & 2010 \\
\hline Informação \& Informação & 1996 \\
\hline Informação \& Sociedade: Estudos & 1991 \\
\hline Informação em Pauta & 2016 \\
\hline InTexto & 1997 \\
\hline Liinc em Revista & 2005 \\
\hline Logeion Filosofia da Informação & 2014 \\
\hline Perspectivas em Ciência da Informação & 1996 \\
\hline Perspectivas em Gestão \& Conhecimento & 2011 \\
\hline Ponto de Acesso & 2007 \\
\hline Revista Brasileira de Biblioteconomia e Documentação & 1973 \\
\hline Revista da ACB: Biblioteconomia em Santa Catarina & 1996 \\
\hline Revista Digital de Biblioteconomia e Ciência da Informação & 2003 \\
\hline Revista Ibero-Americana de Ciência da Informação & 2008 \\
\hline Tendências da Pesquisa Brasileira em Ciência da Informação & 2008 \\
\hline Transinformação & 1989 \\
\hline
\end{tabular}

Fonte: Elaborado pelos autores (2018).

Acerca da produção em teses e dissertações, a busca foi realizada, em dois bancos: o primeiro mantido pelo Instituto Brasileiro de Informação em Ciência e Tecnologia (IBICT) e o segundo pela Coordenação de Aperfeiçoamento de Pessoal de Nível Superior (CAPES). A estratégia de busca utilizada para o banco do IBICT foi "marketing AND ciência da informação" (delimitando por assunto e sem filtro cronológico) e no banco da CAPES "marketing AND ciência da informação" também foi utilizado no campo de busca, mas atribuindo o filtro "Nome do programa" e com uma delimitação cronológica instituída pelo próprio recurso, que somente traz resultados de origem da Plataforma Sucupira entre 2013 e 2017.

Quanto aos anais do Enancib, foram utilizados das sete últimas edições do evento, a saber:

- $\quad$ XVII edição em 2017, Marília, SP

- $\quad$ XVII edição em 2016, em Salvador, BA

- $\quad$ XVI edição em 2015, em João Pessoa, PB;

- XV edição em 2014, em Belo Horizonte, MG;
- $\quad$ XIV edição em 2013, em Florianópolis, SC;

- $\quad$ XIII edição em 2012, no Rio de Janeiro, RJ;

- $\quad$ XII edição em 2011, em Brasília, DF.

\section{DISCUSSÃO DOS RESULTADOS}

Nesta seção são apresentados e discutidos os resultados do levantamento realizado nas três fontes de informação que compõem o universo desta pesquisa. Todas as buscas foram realizadas em janeiro de 2018.

\section{I Produção em artigos}

Da relação de 28 periódicos científicos de acesso aberto, foi realizada uma pesquisa em cada uma das interfaces a partir da ferramenta "Search" ou "Pesquisa", disponibilizada pelo próprio SEER/OJS, sistema que gerencia estas fontes de informação.

Nesta primeira pesquisa, o número de artigos publicados sobre "marketing" foi de 336, 
referente a 44 anos de produção científica. Deste primeiro levantamento, um filtro foi aplicado no intuito de destacar artigos que somente tivessem o termo "marketing" no resumo ou como uma das palavras-chave. Esta ação foi necessária uma vez que os resultados apresentados por esta estratégia de busca traziam artigos que tinham o termo no decorrer do texto e nas referências, sendo mencionado de maneira "periférica", sem ser realmente assunto da publicação. Isso fez com que o número de artigos caísse para 98, respectivos a 21 periódicos, consagrando-se assim como o corpus de análise. O gráfico 1 demonstra o número de publicações ao longo dos anos.

Gráfico 1: Distribuição do número de publicações sobre marketing em periódicos brasileiros da Ciência da Informação ao longo dos anos

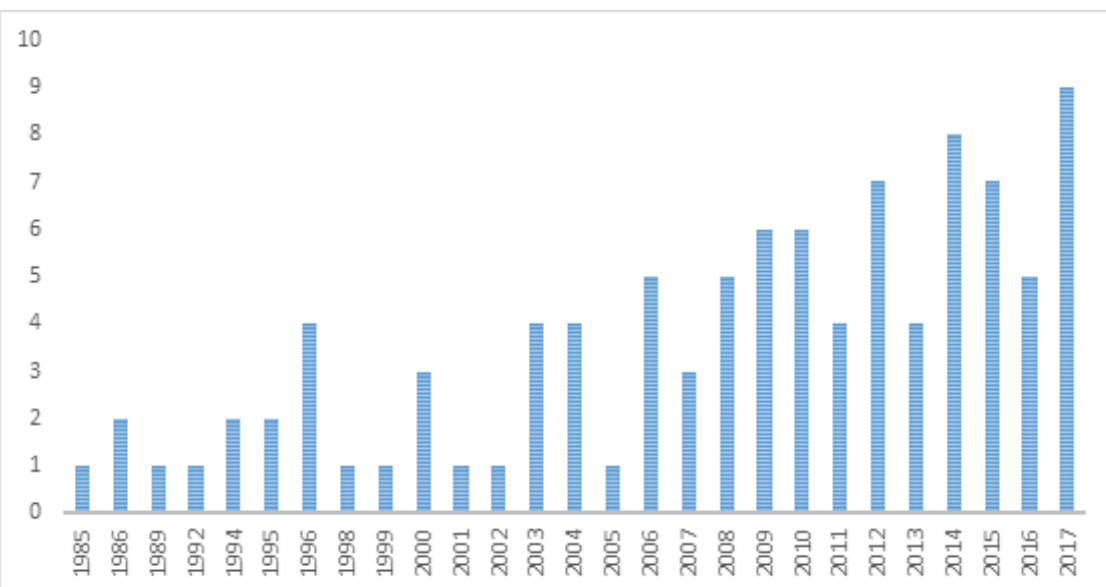

Fonte: Elaborado pelos autores (2018).

A primeira publicação sobre marketing em periódico científico de acesso aberto é decorrente do ano de 1985, um artigo da Revista Ciência da Informação, por Silas Marques de Oliveira intitulado "Marketing e sua aplicação em bibliotecas: uma abordagem preliminar". O texto analisou vários conceitos de marketing aliando-os com o contexto das bibliotecas, além de apresentar técnicas específicas que deveriam ser colocadas em prática por bibliotecários (como pesquisa de mercado, segmentação e marketing mix) e finaliza com um alerta sobre a miopia em marketing e os elementos que compõem um plano do mesmo (OLIVEIRA, 1985).

Ao longo das próximas décadas, o número de artigos só cresceu, sendo os anos 1980 iniciando com 4 textos, 1990 com 10, 2000 com 35 e a partir de 2010 com 49 textos. Um motivador para este crescente seria a forte associação existente entre o trabalho efetuado entre marketing e as tecnologias da informação e comunicação, principalmente mídias sociais.

\begin{abstract}
Dentre os periódicos que mais publicaram sobre o tema, Ciência da Informação aparece em primeiro lugar com 14 textos; Biblionline e Perspectivas em Ciência da Informação com 9 cada; Comunicação e Informação com 8; Biblios com 7; Em Questão com 6; Informação \& Informação, Informação \& Sociedade, Revista da ACB e Revista Digital de Biblioteconomia e Ciência da Informação e Transinformação com 5 artigos cada; Ponto de Acesso, Encontros Bibli e Revista Brasileira de Biblioteconomia e Documentação com 3 artigos cada; Ágora, InTexto, InCID e Revista IberoAmericana de Ciência da Informação com 2 cada e com um artigo somente os periódicos Brazilian Journal of Information Science, Folha de Rosto , Perspectivas em Gestão \& Conhecimento.

Quanto às autorias, foram identificados 151 autores, a maioria tendo escrito somente um artigo. A tabela 1 apresenta os quais mais produziram sobre o assunto e os anos destas publicações.
\end{abstract}


Tabela 1: Autores mais produtivos em periódicos de acesso aberto

\begin{tabular}{|l|c|l|}
\hline \multicolumn{1}{|c|}{ AUTOR } & ARTIGOS & \multicolumn{1}{c|}{ ANO (No DE ARTIGOS) } \\
\hline Sueli Angelica do Amaral & 11 & $\begin{array}{l}1991(1), 1996 \text { (1), 2000 (1), 2001 (1), 2005 (1), 2008 } \\
(2), 2009 \text { (1), 2011 (1) e 2013 (1), 2017 (1) }\end{array}$ \\
\hline Alzira Karla Araujo da Silva & 5 & 2000 (1), 2006 (2), 2007 (1) e 2011 (1) \\
\hline Emeide Nóbrega Duarte & 3 & 2000,2010 e 2017 \\
\hline Gustavo Henrique de Araújo Freire & 3 & 2010,2012 e 2015 \\
\hline Anna C. T. Monteiro de Barros & 2 & 1995 e 1996 \\
\hline Cristiano Santana Costa & 2 & $2015(2)$ \\
\hline Eduardo Silva Alentejo & 2 & 2010,2013 \\
\hline Elaine R. de Oliveira Lucas & 2 & 2006 e 2007 \\
\hline Heloisa Maria Ottoni & 2 & 1996 (2) \\
\hline Isa Maria Freire & 2 & $2015(2)$ \\
\hline Luan Henrique Giroto Ferreira & 2 & $2017(2)$ \\
\hline Márcio Bezerra da Silva & 2 & 2011 e 2015 \\
\hline Maria Cristina Comunian Ferraz & 2 & 2003 e 2009 \\
\hline Murilo Bastos da Cunha & 2 & 1989 e 2015 \\
\hline Nicole Amboni de Souza & 2 & 2006 e 2007 \\
\hline Rosângela Formentini Caldas & 2 & $2017(2)$ \\
\hline Silas Marques de Oliveira & 2 & 1985 e 2003 \\
\hline Sofia Galvão Baptista & 2 & 2009,2013 \\
\hline
\end{tabular}

Fonte: Elaborado pelos autores (2018).

Sueli Angelica do Amaral, identificada como a autora mais produtiva sobre o tema, concluiu seu doutorado em 1998 pela Universidade de Brasília, com a tese "Impacto das atividades de marketing relativas à promoção de serviços no Centro de Informações Nucleares da Comissão Nacional de Energia Nuclear". Lidera o grupo de pesquisa "Marketing da Informação", que em 2018 completa 20 anos de existência ${ }^{2}$.

Com um olhar mais conceitual, de fundamentar teoricamente o Marketing, foram categorizados 43 textos. Sobre os espaços de aplicação do Marketing, a maior concentração

2 Conforme informações obtidas no Diretório de Grupos de Pesquisa do CNPq: http://dgp.cnpq.br/dgp/espelhogrupo/6473222870660670 (Acesso em: 25 maio 2018). estabeleceu-se nas bibliotecas universitárias (22 artigos), seguido das bibliotecas especializadas (9 artigos), arquivos (7 artigos), biblioteca pública (4 artigos) e biblioteca escolar (somente 1 artigo).

O marketing de serviços foi encontrado em 15 artigos, o de produtos em 12 e no espaço da biblioteca como um todo, resultou em 7 artigos. Quando se tratava de marketing via sites, mídias sociais ou outras plataformas digitais, ou seja, quando se tratava de marketing digital, 25 artigos trataram sobre o tema.

Fora destas categorias gerais que foram delimitadas antes da pesquisa, outras temáticas de trabalho sobre o Marketing foram observadas conforme apresentado na tabela 2: 
Tabela 2: Outras temáticas sobre Marketing na produção nacional em periódicos de acesso aberto

\begin{tabular}{|l|c|}
\hline \multicolumn{1}{|c|}{ TEMA } & ARTIGOS \\
\hline Empresas privadas & 6 \\
\hline Marketing pessoal/profissional do bibliotecário & 4 \\
\hline Política & 3 \\
\hline Marketing científico & 2 \\
\hline Agências de publicidade & 1 \\
\hline Arquitetura da informação & 1 \\
\hline Centro de pesquisa & 1 \\
\hline Produções culturais & 1 \\
\hline Propriedade intelectual & 6 \\
\hline
\end{tabular}

Fonte: Elaborado pelos autores (2018).

Alguns dos temas supracitados, um tanto incomuns na produção científica da Ciência da Informação (política, produções culturais e agências de publicidade, por exemplo), são resultantes de periódicos de departamentos com distintos programas de pós-graduação, como Comunicação, mas onde havia a presença do programa em Ciência da Informação.

O "marketing pessoal/profissional do bibliotecário" também se destaca na produção. São trabalhos que buscam vislumbrar o reconhecimento do profissional mediante os produtos, serviços e demais ações que desenvolve.

\subsection{Produção em teses e dissertações}

Nas buscas aos dois bancos de teses e dissertações, o número de documentos encontrados foi de 30 trabalhos (após análise de resumo e das palavras-chave, com a finalidade de observar se Marketing era realmente objeto de estudo).

O ano de 2001 foi o qual contabilizou maior número de defesas, totalizando em quatro trabalhos. Os anos de 1998 e 2002 figuram com três defesas cada; 1996, 2007, 2012 e 2013 apresentam-se com dois trabalhos em cada. Os demais anos possuem somente um registro em cada, sendo 1987 o mais antigo, que se refere a dissertação de Edna Lucia da Silva, "Conceitos de marketing utilizados no planejamento e avaliação de sistemas de informação e bibliotecas: um modelo de metodologia aplicado a biblioteca universitária da UFSC", defendida na UFRJ.

Sobre a origem das instituições, a Universidade de Brasília destaca-se com doze documentos em virtude de seu Programa de Pósgraduação em Ciência da Informação possuir consagrado grupo de pesquisa, registrado em 1998 no Diretório dos Grupos de Pesquisa no Brasil do CNPq, chamado "Marketing da Informação".

Em seguida, a Universidade Federal do Rio de Janeiro apresenta 7 trabalhos, Universidades Federais da Bahia e Paraíba com 3 cada uma; com 2 trabalhos cada a PUC de Campinas e Universidade Federal de Minas Gerais e, por fim, a Universidade de São Paulo com um registro. O quadro 2 apresenta a relação das dissertações e teses, com seus respectivos autores, de programas de pós-graduação em Ciência da Informação que retrataram o marketing em seus estudos. 
Quadro 2: Dissertações e teses sobre Marketing por pesquisadores brasileiros da Ciência da Informação

\begin{tabular}{|c|c|c|}
\hline TÍTULO & AUTORIA & INSTITUIÇÃO/ANO \\
\hline $\begin{array}{l}\text { Modelo para o desenvolvimento de campanhas } \\
\text { de comunicação de marca para instituições } \\
\text { de ensino superior apoiado pela gestão da } \\
\text { informação e inteligência competitiva }\end{array}$ & Wagner José de Mello & PUC Campinas/2008 \\
\hline $\begin{array}{l}\text { Marketing de relacionamento em bibliotecas: } \\
\text { uma ferramenta de comunicação em ambiente } \\
\text { web para socialização da informação }\end{array}$ & Walqueline da Silva Araújo & UFPB/2015 \\
\hline $\begin{array}{l}\text { Sistemas de informação de clientes e marketing } \\
\text { de relacionamento para obtenção de vantagem } \\
\text { competitiva em bancos comerciais }\end{array}$ & Cid Gonçalves Filho & UFMG/1996 \\
\hline $\begin{array}{l}\text { O processo de mediação no contexto do regime } \\
\text { de informação: a construção de um espaço } \\
\text { virtual de comunicação na web para a CPAD/ } \\
\text { UFPB }\end{array}$ & Felipe Sá Brasileiro & UFPB/ 2013 \\
\hline $\begin{array}{l}\text { O marketing nas bibliotecas brasileiras de } \\
\text { Geociências e Tecnologia Mineral }\end{array}$ & Sueli Angelica do Amaral & UnB/1990 \\
\hline $\begin{array}{l}\text { Estratégias de marketing aplicadas em uma } \\
\text { unidade de informação do exército }\end{array}$ & Mônica Simas Santos & UFRJ/1996 \\
\hline A segmentação de clientes em bibliotecas & Denise Rodrigues So & USP / 2007 \\
\hline $\begin{array}{l}\text { Estratégias de marketing na Internet para } \\
\text { websites de periódicos brasileiros em Ciência } \\
\text { da Informação }\end{array}$ & Ricardo Matos Chaim & UnB/2001 \\
\hline $\begin{array}{l}\text { Informação e marketing de relacionamento: } \\
\text { desafios e oportunidades do comércio eletrônico }\end{array}$ & Alessandra Mendes de Farias & UFRJ/2001 \\
\hline $\begin{array}{l}\text { Biblioteca universitária em busca de maior } \\
\text { visibilidade: gestão da informação e o uso de } \\
\text { técnicas e ferramentas de marketing }\end{array}$ & Raul Marques Leite de Souza & UFBA/2011 \\
\hline $\begin{array}{l}\text { Análise do sistema de informações gerenciais } \\
\text { Sisproweb do Ministério Público do Distrito } \\
\text { Federal e Territórios sob a ótica do marketing } \\
\text { da informação }\end{array}$ & Andrea Vieira Santos & UnB/2012 \\
\hline Marketing na gestão de bibliotecas públicas & Jovenilda Freitas dos Santos & UFBA/2012 \\
\hline $\begin{array}{l}\text { Biblioteca virtual temática em saúde: } \\
\text { interatividade com usuário leigo }\end{array}$ & Regina Goulart Lourenço & UFRJ/2013 \\
\hline $\begin{array}{l}\text { Estratégias de informação e modelos } \\
\text { organizacionais: o espaço da administração e da } \\
\text { comunicação na Ciência da Informação }\end{array}$ & $\begin{array}{l}\text { Regina Célia Montenegro de } \\
\text { Lima }\end{array}$ & UFRJ/1997 \\
\hline $\begin{array}{l}\text { Marketing em unidades de informação: estudo } \\
\text { de caso na Biblioteca do Centro de Pesquisa } \\
\text { Agropecuária dos Cerrados, CPAC, da } \\
\text { Embrapa: Pesquisa qualitativa de opinião }\end{array}$ & Antonio Felipe Galvão da Silva & UnB/1998 \\
\hline
\end{tabular}




\begin{tabular}{|c|c|c|}
\hline TÍTULO & AUTORIA & INSTITUIÇÃO/ANO \\
\hline $\begin{array}{l}\text { Pesquisa de marketing para a segmentação de } \\
\text { público-alvo: estudo de comportamento, hábitos } \\
\text { e preferências de usuários da informação em } \\
\text { arte }\end{array}$ & Antonio Felipe Galvão da Silva & $\mathrm{UnB} / 2003$ \\
\hline $\begin{array}{l}\text { A busca da informação em bases de dados e } \\
\text { necessidade de treinamento: um estudo da } \\
\text { Biblioteca Central da Universidade de Brasília }\end{array}$ & José Neuton Lopes & UnB/2004 \\
\hline $\begin{array}{l}\text { A interpretação da informação oriunda do } \\
\text { ambiente externo por gerentes }\end{array}$ & Liliam Pacheco Pinto & UFMG/2002 \\
\hline $\begin{array}{l}\text { Conceitos de marketing utilizados no } \\
\text { planejamento e avaliação de sistemas de } \\
\text { informação e bibliotecas: um modelo de } \\
\text { metodologia aplicado a biblioteca universitária } \\
\text { da UFSC }\end{array}$ & Edna Lucia da Silva & UFRJ/1987 \\
\hline $\begin{array}{l}\text { Construindo um modelo estratégico na área de } \\
\text { marketing a partir do sistema de informações } \\
\text { gerenciais apoiado pela inteligência competitiva } \\
\text { e pelo monitoramento ambiental }\end{array}$ & Andrea de Luiz Cortez & UFRJ/2002 \\
\hline $\begin{array}{l}\text { Enfoque de marketing no processo de } \\
\text { distribuição de produtos de informação em } \\
\text { unidades de informação: estudo de caso de } \\
\text { revista Pesquisa Agropecuária Brasileira da } \\
\text { Embrapa }\end{array}$ & Maria de Fátima Castro Bayma & $\mathrm{UnB} / 2000$ \\
\hline $\begin{array}{l}\text { O marketing institucional do INMETRO: para } \\
\text { que e para quem? }\end{array}$ & $\begin{array}{l}\text { Tatiana Ruback Cascardo } \\
\text { Vieira }\end{array}$ & UFRJ/1998 \\
\hline $\begin{array}{l}\text { Marketing em serviços de informação } \\
\text { governamental na web: estudo experimental de } \\
\text { promoção do Portal Rede Governo }\end{array}$ & Wagner Junqueira de Araújo & UnB/2001 \\
\hline $\begin{array}{l}\text { Avaliação de sites web centrada no usuário: um } \\
\text { estudo de caso sob a ótica de marketing }\end{array}$ & Tatiana de Almeida Furquim & UnB/2002 \\
\hline $\begin{array}{l}\text { Omarketing digital nas bibliotecas universitárias } \\
\text { públicas de Salvador }\end{array}$ & Nivea Camara Rocha de Souza & UFBA/2016 \\
\hline $\begin{array}{l}\text { Impacto das atividades de marketing relativas à } \\
\text { promoção junto aos usuários reais do sonas-inis } \\
\text { e do servis-inis no Centro de informação nuclear } \\
\text { da Comissão Nacional de Energia Nuclear }\end{array}$ & Sueli Angelica do Amaral & UnB/1998 \\
\hline $\begin{array}{l}\text { Gestão da informação de marketing para } \\
\text { inteligência competitiva em shopping centers } \\
\text { do Distrito Federal }\end{array}$ & Carlos Eduardo Azevedo & UnB/2005 \\
\hline $\begin{array}{l}\text { Conhecimento e percepção de Marketing; } \\
\text { gerentes das Bibliotecas universitárias públicas } \\
\text { do estado do Paraná, Brasil }\end{array}$ & Angela Maria de Oliveira & PUC Campinas/2001 \\
\hline $\begin{array}{l}\text { O Conceito de Marketing e as Atividades de } \\
\text { Gerência em Bibliotecas Universitárias }\end{array}$ & Marilene Arcangela M. Martelli & UFPB/1999 \\
\hline $\begin{array}{l}\text { Gestão da informação sobre a satisfação de } \\
\text { clientes e orientação para o mercado }\end{array}$ & Edmundo Brandão Dantas & $\mathrm{UnB} / 2007$ \\
\hline
\end{tabular}

Fonte: Elaborado a partir dos bancos de teses e dissertações do IBICT e da Capes (2018). 
Diferentemente da produção em artigos, aqui se percebem outras abordagens que não focam em sua maioria no espaço das bibliotecas, mas sim em outras unidades de informação. Há um olhar também mais estratégico imbuído nos trabalhos percebido a partir das leituras dos resumos e da relação de palavras-chave (como "informação para negócios", "inteligência competitiva", "oferta de informação" e "segmentação de mercado").

O nível de detalhamento nestes estudos, alinhando-se com outras áreas do conhecimento, é um exemplo claro da interdisciplinaridade da Ciência da Informação destacada na introdução deste artigo.

\subsection{Produção no ENANCIB}

Sobre a produção nos anais do Enancib, foram recuperados somente seis trabalhos sobre Marketing, sendo que de 2011 e 2017 não foram encontradas evidências a respeito do tema. As buscas foram realizadas a partir do termo "marketing". O quadro 3 relaciona estes trabalhos com os seus respectivos anos $\mathrm{e}$ autorias.

Quadro 3: Produções sobre Marketing nos anais do Enancib entre os anos 2011-2017

\begin{tabular}{|l|l|l|}
\hline \multicolumn{1}{|c|}{ TÍTULO } & ANO & \multicolumn{1}{|c|}{ AUTORIA } \\
\hline Estudo de usuário e marketing da informação & 2012 & S. A. do Amaral \\
\hline $\begin{array}{l}\text { Marketing na gestão das bibliotecas públicas de } \\
\text { Salvador/BA: obstáculos para sua adoção }\end{array}$ & 2013 & J. F. Santos e N. M. L. Lubisco \\
\hline $\begin{array}{l}\text { Satisfação de clientes, marketing e serviços de } \\
\text { informação }\end{array}$ & 2014 & S. A. do Amaral e E. B. Dantas \\
\hline $\begin{array}{l}\text { Fundamentos teóricos de orientação de marketing na } \\
\text { gestão de serviços informativos }\end{array}$ & 2015 & S. A. do Amaral \\
\hline $\begin{array}{l}\text { Informação, Marketing e negociação no mercado: } \\
\text { reflexões éticas }\end{array}$ & 2015 & R. V. Satur \\
\hline $\begin{array}{l}\text { O uso do Facebook para a divulgação das bibliotecas } \\
\text { universitárias federais do nordeste }\end{array}$ & 2016 & $\begin{array}{l}\text { R. V. Satur, R. R. Santos, A. K. A. da } \\
\text { Silva e N. T. O. Duarte }\end{array}$ \\
\hline
\end{tabular}

Fonte: Elaborado pelos autores (2018).

Aqui a abordagem está mais retratada em serviços de informação do que propriamente em unidades de informação. Pode-se perceber também que não há uma relação entre os pesquisadores elencados na tabela 4 a partir dos anos 2010 com os Anais do Enancib. Exceto pelos trabalhos de Amaral, nenhum outro autor deu continuidade aos seus estudos com resultados nas edições analisadas do evento.

\section{CONSIDERAÇÕES FINAIS}

A Ciência da Informação e o Marketing são duas áreas em franca expansão, bastante conectadas com as tecnologias da informação, interdisciplinares e com uma grande dimensão social e humana, ou seja, ciências pós-modernas sob o olhar de Saracevic (1996). Em quarenta e quatro anos de produção científica no contexto brasileiro, algumas considerações podem ser apontadas.

Se pensarmos nas correntes teóricas da Ciência da Informação propostas por Araújo (2014), podemos apresentar uma relação com duas delas. A primeira é o estudo dos fluxos de informação científica, pioneiro da área, que com os fundamentos teóricos apresentados neste artigo possuem estreita ligação. A segunda das correntes é a gestão da informação e do conhecimento, uma vez que o Marketing trabalha fortemente com a gestão da informação (seja esta proveniente dos clientes, seja do próprio produto ou serviço).

Muitas das produções, principalmente proveniente dos artigos, tratam logo no resumo o marketing no âmbito da divulgação, principalmente a partir dos anos 2000 com 
a influência da Internet e das mídias sociais. Esta característica é limitadora e recorrente, proveniente de uma confusão conceitual dos termos, sem um limiar muito definido entre comunicação, divulgação e marketing.

O principal espaço presente na produção é o das bibliotecas, que é reflexo de uma aproximação teórica entre a Biblioteconomia e a Ciência da Informação. A mesma questão apontada no parágrafo anterior também pode ser estendida aqui, onde se poderia pensar a biblioteca como um mercado, de maneira mais estratégica a qual o Marketing se propõe e não somente à forma de divulgá-la.

Ambas as áreas são relativamente novas se comparadas com outras. Acompanham rapidamente as transformações socioeconômicas e mais recentemente com forte influência das tecnologias de informação. Novos esforços acadêmicos precisam ser construídos com a finalidade de congraçar com mais afinco o Marketing e a Ciência da Informação.

Recomenda-se para pesquisas futuras, além da continuidade de contribuições teóricas que consagrem a natureza do conceito, relações com as mais recentes escolas de Marketing, que foram mencionadas na seção 2. Aliar o que há de mais emergente proposto por pesquisadores do Marketing com o os da Ciência da Informação também é recomendável para delimitar, teoricamente, deficiências e avanços.

Artigo recebido em I5/0I/2018 e aceito para publicação em 07/06/2018

\section{MARKETING IN BRAZILIAN INFORMATION SCIENCE: four decades of production}

ABSTRACT This article presents a survey and analysis of the Brazilian intellectual production about Marketing in information sources of Information Science. And exploratory and initially quantitative research was carried out in all open access scientific journals active in Information Science, in a temporal coverage from 1972 to December 2017. Then, the survey is carried out in the dissertation and thesis databases of the Brazilian Institute of Scientific and Technological Information (IBICT) and the Coordination for the Improvement of Higher Education Personnel (Capes), without temporal delimitation. The research is finalized in a third information source, which are the proceedings of the National Seminar of Research in Information Science (Enancib) of the last seven years. To all data collected, a qualitative analysis was carried out with the purpose of pointing out some characteristics of the production. It was verified that there is a strong relation of associating marketing with the communication, dissemination and technology in different typologies of libraries (academic, school, public and specialized) and in few other units of information, like research centers. Rare are the texts that sought to reflect on the concept in a more theoretical way, with contributions and relations along with Information Science.

Keywords: $\quad$ Marketing. Information Science. Scientific production.

\section{REFERÊNCIAS}

ALDERSON, W. Dynamic marketing behavior: a functionalist theory of marketing. Homewood, Illinois: Richard D. Irwin, 1965.

ARAÚJO, C. A. A. Correntes teóricas da Ciência da Informação. Ci. Inf., Brasília, v. 38, n. 3, p. 192-204, set./dez., 2009.
ARAÚJO, C. A. A. O conceito de informação na Ciência da Informação. Inf. \& Soc.: Est., João Pessoa, v. 20, n. 3. p. 95-105, set./dez. 2010.

ARAÚJO, C. A. A. O que é Ciência da Informação? Inf. Inf., Londrina, v. 19, n. 1, p. 1-30, jan./abr. 2014.

ANCIB. Fórum de Coordenadores de Grupos de Trabalho da Ancib. Publicado em: [20??]. 
Disponível em: <http://gtancib.fci.unb.br/>. Acesso em: 26 ago. 2016.

BARTELS, R. The identity crisis in Marketing. Journal of Marketing, v. 38, n. 4, p. 73-76, Fall 1974.

BARTELS, Robert. The history of marketing thought. Columbus, OH: Grid, 1976.

BAGOZZI, R. Marketing as an organized behavioral system of exchange. Journal of Marketing, v. 38, n. 4, p. 77-81, 1974.

BAGOZZI, R. Marketing as exchange. Journal of Marketing, v. 39, n. 4, p. 32-39, 1975 a.

BAGOZZI, R. Social exchange in Marketing. Journal of the Academy of Marketing Science, v. 3, p. 314-327, 1975b.

BEEM, E. R. The beginnings of the consumer movement. In: KELLEY, W. T. New consumerism: selected readings. Columbus, $\mathrm{OH}$ : Grid, 1973.

BORKO, H. Information Science: what is it? American Documentation, v. 19, p. 3-5, 1968.

BUCKLAND, M. K. Information as a thing. JASIS, v.42, n.5, p.351-360, June 1991.

CAPURRO, R. Epistemologia e ciência da informação. In: ENCONTRO NACIONAL DE PESQUISA EM CIÊNCIA DA INFORMAÇÃO, 5., 2003, Belo Horizonte. Anais... Belo Horizonte: Associação Nacional de Pesquisa e Pós-Graduação em Ciência da Informação e Biblioteconomia, 2003.
DUDDY, E. A.; REVZAN, D. A. Marketing: an institutional approach. New York: McGraw-Hill Book Company, 1947.

FREIRE, G. H. Ciência da informação: temática, histórias e fundamentos. Perspectivas em Ciência da Informação, Belo Horizonte, v. 11, n. 1, p. 6-19, jan./abr. 2006.

GRÖNROOS, C. Relationship Marketing as promise management. In: MACLARAN, P.; SAREN, M.; STERN, B.; TADAJEWSKI, M. The SAGE Handbook of Marketing Theory. Thousand Oaks: SAGE Publications, 2013.

GUNDLACH, G. T. The American Marketing Association`s 2004 definition of Marketing: perspectives on its implications for scholarship and the role and responsability of marketing in society. Journal of Public Policy \& Marketing, v. 26, n. 2, p. 243-250, 2007.

GUNDLACH, G. T.; WILKIE, W. L. The American Marketing Association's new definition of marketing: perspective and commentary on the 2007 revision. Journal of Public Policy \& Marketing, v. 28, n. 2, p. 259-264, 2009.

HAMPTON, D. R. Administração contemporânea: teoria, prática e casos. 3. ed. São Paulo: Makron Books, 2005.

HOBSBAWN, E. J. A era dos extremos: o breve século XX. São Paulo: Companhia das Letras, 2008.

HUNT, S. The nature and scope of Marketing. Journal of Marketing, v. 40, n. 3, p. 17-28, Summer 1976.

HUNT, S. D.; BURNETT, J. J. The macromarketing/micromarketing dichotomy: a 
taxonomical model. Journal of Marketing, v. 46, p. 11-26, Summer, 1986.

KOTLER, P.; KARTAJAYA, H.; SETIAWAN, I. Marketing 3.0: as forças que estão definindo o novo marketing centrado no ser humano. Rio de Janeiro: Elsevier, 2010.

KOTLER, P.; KELLER, K. L. Administração de marketing. 14. ed. São Paulo: Pearson Prentice Hall, 2012.

KOTLER, P.; LEVY, S. Broadening the concept of Marketing. Journal of Marketing, v. 33, n. 1, p. 10-15, 1969a.

KOTLER, P.; LEVY, S. A new form of Marketing myopia: rejoinder to Professor Luck. Journal of Marketing, v. 33, n. 3, p. 55-57, 1969 b.

KOTLER, P. A generic concept of Marketing. Journal of Marketing, v. 36, n. 2, p. 46-54, 1972.

LAS CASAS, Alexandre Luzzi. Marketing: conceitos, exercícios, casos, 6. ed. São Paulo: Atlas, 2004.

LUCK, D. Broadening the concept of Marketing: too far. Journal of Marketing, v. 33, n. 3, p. 53-54, 1969.

MCINNES, W. A conceptual approach to marketing. In: ALDERSON, W.; COX, R.; SHAPIRO, S. J. Theory in Marketing. Homewood, Illinois: Richard D. Irwin, 1964.

REES, A.; SARACEVIC, T. Education for information science and its relation to librarianship. [S.1.]: [s.n.], 1967.
RYAN, F. Functional concepts in market distribution. Harvard Business Review, v. 13, p. 205-224, Jan. 1935.

SARACEVIC, T. Ciência da informação: origem, evolução e relações. Perspectivas em Ciência da Informação, Belo Horizonte, v. 1, n. 1, p. 41-62, jan./jun. 1996.

SHARMA, M. Evolution of marketing concept (with diagram). YourArticleLibrary, 2015. Disponível em: <http:/ / www.yourarticlelibrary. $\mathrm{com} /$ marketing/evolution-of-marketingconcept-with-diagram/48793/>. Acesso em: 27 ago. 2016.

SHERA, J. H.; CLEVELAND, D. B. History and foundations of Information Science. ARIST, v. 12, p. 249-275, 1977.

SHETH, J. D. A review of buyer behavior. Management Science, v. 13, Aug. 1967, p. B718-B756.

SHETH, J. D.; GARDNER, D. M.; GARRETT, D. E. Marketing theory: evolution and evaluation. New York: John Wiley \& Sons, 1988.

SHETH, J. D. The double helix of marketing: the complementary relationship between marketing history and marketing theory. Marketing Theory, v. 11, n. 4, December 2011, p. 503-505.

TAYLOR, R. S. Professional aspects of information science and technology. In: CUADRA, C. A. Annual Review of Information Science and Technology. New York: John Wiley, 1966.

VARGO, S. L.; LUSCH, R. F. Evolving to a new dominant logic for Marketing. Journal of Marketing, v. 68, n. 1, p. 1-17, 2004. 
WEBSTER JUNIOR, F. E. The changing role of Marketing in the corporation. Journal of Marketing, v. 56, n. 4, p. 1-17 1992.

WEBSTER JUNIOR, F. E. Defining the new Marketing concept. Marketing Management, v. 2, n. 4, p. 22-31, 1994a.

WEBSTER JUNIOR, F. E. Executing the new Marketing concept. Marketing Management, v. 3, n. 1, p. 9-16, 1994 b.
WILKIE, W. L.; MOORE, E. S. Scholarly research in Marketing: exploring the " 4 Eras" of thought development. Journal of Public Policy \& Marketing, v. 22, Fall 2003, p. 116-146.

ZINS, C. Conceptions of information science. JASIST, v. 58, n. 3, p. 335-350, 2007. 